\title{
REPORT
}

\section{The role of plant species in biomass production and response to elevated $\mathrm{CO}_{2}$ and $\mathrm{N}$}

Joseph M. Craine ${ }^{1 *}$,

Peter B. Reich , G. David Tilman', David Ellsworth ${ }^{3}$, Joseph

Fargione ${ }^{1}$, Johannes Knops ${ }^{4}$ and

Shahid Naeem ${ }^{5}$

${ }^{1}$ Department of Ecology,

Evolution and Behavior,

University of Minnesota, Saint

Paul, MN 55108, USA

${ }^{2}$ Department of Forest

Resources, University of

Minnesota, Saint Paul, MN

55108, USA

${ }^{3}$ School of Natural Resources

and Environment, University of

Michigan, Ann Arbor, MI 48109,

USA

${ }^{4}$ School of Biological Sciences,

University of Nebraska, Lincoln,

NE 68588, USA

${ }^{5}$ Department of Biology,

University of Washington,

Seattle, WA 98195, USA

*Correspondence: E-mail:

crain010@umn.edu

\begin{abstract}
In an experiment that factorially manipulated plant diversity, $\mathrm{CO}_{2}$, and $\mathrm{N}$, we quantified the effects of the presence of species on assemblage biomass over 10 time points distributed over 5 years. Thirteen of the 16 species planted had statistically significant effects on aboveground and/or belowground biomass. Species differed dramatically in their effects on biomass without any relationship between aboveground and belowground effects. Temporal complementarity among species in their effects seasonally, successionally, and in response to a dry summer maintained the diversity-biomass relationships over time and may be the cause behind higher diversity plots having less variation in biomass over time. The response of plant biomass to elevated $\mathrm{N}$, but not $\mathrm{CO}_{2}$, was at times entirely dependent on the presence of a single species.
\end{abstract}

\section{Keywords}

BioCON, biodiversity, Cedar Creek Natural History Area, grassland, global change.

\section{INTRODUCTION}

Ecosystems worldwide are shifting in plant composition and diversity as they lose native species and non-native species invade or are introduced (Chapin et al. 2000). Simultaneously, ecosystems are also being subjected to increasingly greater supplies of atmospheric $\mathrm{CO}_{2}$ and inorganic nitrogen (N) (Vitousek 1994; Sala et al. 2000; Shaw et al. 2002). The productivity of an ecosystem and its response to elevated atmospheric $\mathrm{CO}_{2}$ and $\mathrm{N}$ deposition depend on the richness and composition of the plant assemblage (Hector et al. 1999; Niklaus et al. 2001; Tilman et al. 2001; Reich et al. 2001a; He et al. 2002). Yet, our ability to understand ecosystem responses to changes in $\mathrm{CO}_{2}, \mathrm{~N}$, or plant diversity is limited by our understanding of the roles of individual species and species interactions in the functioning of ecosystems with diverse plant assemblages.
For example, the greater productivity of high diversity assemblages is caused more by complementarity than by sampling effects (Loreau \& Hector 2001; Tilman et al. 2001), yet how species interactions generate complementarity is poorly understood. The lack of understanding of these interactions is especially acute for aggregate properties of the ecosystem, such as belowground biomass accumulation, for which the contribution of individual species cannot be directly measured. Even if at any one point in time plots with higher plant diversity have greater biomass because of the increasing likelihood of a given species being present at high diversity (i.e. sampling effect) (Aarssen 1997; Huston 1997), different species could be important at different times. Species can have differential importance along the developmental sequence of an assemblage (Niklaus et al. 2001), can be offset phenologically (Tilman et al. 2001), and respond to weather and climate fluctuations differently (Tilman \& Downing 1994). Similarly, the response of an 
assemblage to elevated $\mathrm{CO}_{2}$ or $\mathrm{N}$ can be dependent on the diversity of the assemblage (Reich et al. 2001a), but any role of individual species in determining the assemblage responses to increases in $\mathrm{CO}_{2}$ or $\mathrm{N}$ have not been quantified.

We created a grassland experiment in 1997 in central Minnesota, USA that factorially combines plant diversity, atmospheric $\mathrm{CO}_{2}$, and $\mathrm{N}$ supply (Reich et al. 2001a). The experiment is designed in a manner that allows detection of the effects of individual species (Allison 1999). The study includes $3592 \times 2 \mathrm{~m}$ plots distributed among six 20-m diameter experimental units (rings). Three rings were exposed to ambient $\mathrm{CO}_{2}$ concentrations $\left(368 \mu \mathrm{mol} \mathrm{mol}^{-1}\right)$ and three to elevated $\mathrm{CO}_{2}\left(560 \mu \mathrm{mol} \mathrm{mol}^{-1}\right)$ using a free-air $\mathrm{CO}_{2}$ enrichment (FACE) system. Soils for the experiment were sandy and each plot was planted in 1997 with one, four, nine, or 16 local species of $\mathrm{C}_{3}$ grasses, $\mathrm{C}_{4}$ grasses, $\mathrm{C}_{3}$ legumes, $\mathrm{C}_{3}$ non-leguminous dicots (forbs). Half of the plots received the equivalent of $4 \mathrm{~g} \mathrm{~N} \mathrm{~m}^{-2}$ year ${ }^{-1}$ in the form of $\mathrm{NH}_{4} \mathrm{NO}_{3}$ over three applications each year. In each plot aboveground biomass and belowground biomass were harvested biennially (mid-June and early August) from 1998 to 2002. Other results from this study are reported in (Craine \& Reich 2001; Craine et al. 2001; Lee et al. 2001; Tjoelker et al. 2001; Reich et al. 2001a,b).

Here, we examine the roles of individual species in determining assemblage-level biomass across a gradient of planted diversity at different resource availabilities over 10 harvests spread across 5 years. We use statistical techniques that quantify the effects of the presence of species and treatments on aboveground and belowground plant biomass without separating the production of a given species and its effects on the production of other species.

If species differ in their effects over time, we examine whether these temporal effects are due largely to "seasonal" differences, "successional" differences, or associated with interannual variation in climate. We refer to consistent differences in species effects between the June and August harvests as "seasonal" differences. Successional differences (sensu Niklaus et al. 2001) in species effects are defined as differences over time that cannot be attributed to variation in short-term climate fluctuations and more likely reflect differences in growth rate and life history characteristics among species or ecosystem properties (e.g. $\mathrm{N}$ cycling rates). These transient changes in species effects are not associated with the immigration of new species, which can be an important aspect of succession outside of experiments that control species pools.

An important consequence in variation in species effects and interactions among species over time is its effect on the variability over time in assemblage biomass. For example, species effects can be temporally complementary and variation in biomass over time will decrease with increasing diversity due to the greater likelihood of more diverse plots containing species with temporally complementary effects. To explore questions of the role of individual species in the responses of assemblages to elevated $\mathrm{CO}_{2}$ and $\mathrm{N}$, we test for statistical interactions between the presence of species and resource treatments that signify differences in biomass response of assemblages based on the presence or absence of a species.

\section{MATERIALS AND METHODS}

The BioCON experiment is located at the Cedar Creek Natural History Area in Minnesota, USA. Plots were established on a secondary successional grassland on sandy soil. Before seeding, plots were tilled, methyl bromide was applied to kill weed seeds, and soils were reinoculated with unfumigated soil. The 16 species used in this study were all native or naturalized to the Cedar Creek Natural History Area and include four $\mathrm{C}_{4}$ grasses (Andropogon gerardii, Boutelona gracilis, Schizachyrium scoparium, Sorghastrum nutans), four $\mathrm{C}_{3}$ grasses (Agropyron repens, Bromus inermis, Koeleria cristata, Poa pratensis), four N-fixing legumes (Amorpha canescens, Lespedera capitata, Lupinus perennis, Petalostemum villosum) and four non-N-fixing herbaceous species (forbs) (Achillea millefolium, Anemone cylindrica, Asclepias tuberosa, Solidago rigida).

A split plot design was used with $\mathrm{CO}_{2}$ treatment as the whole-plot factor, replicated three times among the six rings. The subplot factors of species number and $\mathrm{N}$ treatment were randomly assigned and replicated in individual plots among the six rings. $\mathrm{CO}_{2}$ was added in elevated treatments during all daylight hours generally from early April to late October. Beginning in 1998, half of the plots were amended with $4 \mathrm{~g} \mathrm{~N} \mathrm{~m}^{-2}$ year ${ }^{-1}$, applied over three dates each year. Each plot was planted in 1997 with $12 \mathrm{~g} \mathrm{~m}^{-2}$ of seed partitioned equally among all species planted in a plot. Plots were regularly weeded to remove unwanted species. Monocultures of all species were replicated twice within all four $\mathrm{CO}_{2}$ and $\mathrm{N}$ treatment combinations. The four- and nine-species plots included both random selections from all species and those that were created to enhance contrasts among functional groups. All plots were burned in the spring of 2000 and 2002.

Aboveground biomass was assessed from a $0.1 \mathrm{~m}^{2}$ strip of vegetation clipped from each plot and biomass was separated into species. Belowground biomass was assessed from three $5 \mathrm{~cm}$ diameter $\times 20 \mathrm{~cm}$ deep cores. No one area was sampled for aboveground or belowground biomass twice.

All data analyses were conducted in JMP 4.0 (SAS Institute, Cary, NC, USA). To determine whether biomass increased or decreased with diversity, biomass was regressed against the square root transform of planted diversity. For most simple regressions testing whether biomass increases 
or decreases with planted diversity, $\mathrm{CO}_{2}$ and $\mathrm{N}$ treatments were not included as factors in the model, unless otherwise mentioned.

A repeated measures ANOVA was used to determine the main effects of species and treatments on biomass and statistical interactions between main effects. All main effects were included initially in the models. These included the presence/absence of the $\mathrm{CO}_{2}$ treatment, the $\mathrm{N}$ treatment, and each species in the seed mix. As nested factors $\left(\mathrm{CO}_{2}\right.$ treatment and ring identity) cannot be included in repeated measures, we did not include block identity in the model. Non-significant factors were removed from the model serially in order of increasing $F$, calculating new $F$ values each time a factor is removed. Owing to the large number of factors and the potential for false positive results, a more stringent than usual test of significance was used $(P \geq 0.01)$. For the remaining significant main effects $(P<0.01)$, another model was constructed that included all significant main effects and all potential pairwise interactions among the significant main effects. Non-significant interactions were removed serially in order of increasing $F$ until all the retained variables had $P<0.01$. The well-balanced design of the experiment with a large number of plots with contrasting composition leads to low levels of collinearity among presences of species and species pairs [low variance inflation factors; see Schmid et al. (2002) for a discussion of relevant issues]. This allows main effects and interactions to be tested nonsequentially (Type I SS), although we do test the importance of species richness against the residuals of the models, since the presences of the significant main effects and interactions are highly collinear with richness.

The results of the ANOVA are a statistical description of the effects of the presence/absence of species and treatments on plot-level biomass. In the ANOVA, the intercept of the model approximates the biomass of the average monoculture with no resource treatments, a significant main effect the change in biomass when that factor (such as the presence of a particular species) is present, and a significant statistical interaction among two factors (such as the presence of a pair of species) alters the biomass when both factors are present relative to the sum of the two main effects.

Using the ANOVA approach, a positive statistical interaction implies that the presence of two species yields more biomass than was expected based on the sum of their individual effects. A negative statistical interaction implies that the presence of the two species yields less biomass than was expected based on the sum of their individual effects. Both positive and negative statistical interactions could be indicative of species interactions that cause overyielding. Thus determining whether a pair of species has complementary or facilitating interactions requires examination of both the sign and magnitude of the main effects and statistical interaction. Instead of showing each main effect and the statistical interactions a species was involved in, for visualizing the effects of species over time, we calculated the main effect of the species at a given harvest and added one half of each statistical interaction of which the species was a part. This represents the average effect of a species for when the other species of the statistical interaction was and was not present in the seed mix.

To examine the consequences of not having slowgrowing species that increase their effects over time, we also calculated what the change in biomass with increasing diversity would have been if slow-growing species and interactions involving slow-growing species had not increased their effects over time. We determined the patterns of effects over time using principal components analyses (PCA). A matrix of the estimates of the main effects and statistical interactions both aboveground and belowground (columns) vs. time (rows) were included in the PCA and the analysis run on the correlations among factors. One of the principal components separated slow- and fastgrowing species. We then compared the slopes of the relationships between diversity and (1) mean biomass and (2) predicted biomass without the eight effects that increase the most over time (eight most positive aboveground factors of PCA Axis 1).

We analysed the variance of biomass over time by determining the standard deviation (SD) of biomass for each plot over time, determining the relationship between the SDs and average plot biomass at each diversity level, and comparing it at a common biomass for the four diversity levels (least squares mean). We used a regression model that tested the effects of diversity (categorical), $\mathrm{CO}_{2}, \mathrm{~N}$, and the mean biomass of the plot. This standardizes the SD at a common biomass in a manner that is equivalent to analysing the coefficients of variation, without being subject to inflation of ratios and controlling for differences in biomass among diversity levels. Differences in variance at different diversity levels can be due to compositional differences (McGrady-Steed et al. 1997; Naeem \& Li 1998; Wardle 1998), which we do not separate out here. As such, whether reliability or stability increases or decreases with increasing diversity we cannot answer since we are not partitioning variance associated with compositional differences, only whether the variance of the plots increased or decreased with increasing diversity.

\section{RESULTS}

In a regression of aboveground biomass on planted diversity, aboveground biomass significantly increased with greater species richness for nine of the 10 harvests $(P<0.001$ for all harvests except August 2000, $P=0.67$; 
Fig. 1). In 2000, May-July precipitation was half of the precipitation experienced over the same period in 1999 or 2001 and volumetric soil moisture was often at $4 \%$ (P. Reich, unpublished data). A diversity effect was not present aboveground in August 2000 at any combination of $\mathrm{CO}_{2}$ or $\mathrm{N}$. Belowground, biomass increased with diversity for all 10 harvests $(P<0.001)$. Although the diversity effect was variable in absolute and relative strength over time, there appeared to be no monotonic change in the strength of the diversity effect over time as it was generally maintained both aboveground and belowground throughout the 5 years of sampling (Fig. 1).

Based on the repeated measures ANOVA, the presence of 12 species (three $\mathrm{C}_{3}$ grasses, two $\mathrm{C}_{4}$ grasses, three forbs, and four legumes) significantly $(P<0.01)$ affected aboveground biomass (Fig. 2). There was a wide range in the effects of the presence of species at a given harvest, from $-158 \mathrm{~g} \mathrm{~m}^{-2}$ (Bouteloua, August 2000) to $+446 \mathrm{~g} \mathrm{~m}^{-2}$ (Lespedera, August 2002). The effects of a single species varied considerably over time. For example, among the 10 harvests, the effect of Lespedeza varied by $456 \mathrm{~g} \mathrm{~m}^{-2}$ and that of Lupinus by $376 \mathrm{~g} \mathrm{~m}^{-2}$. Averaged across harvests, the model describes aboveground biomass at each diversity level within $6 \%$ of the mean and little of the variance of the model's residuals $(1 \%)$ is explained by species richness. This implies that the main effects and interactions of the model capture the general relationship between diversity and aboveground biomass.

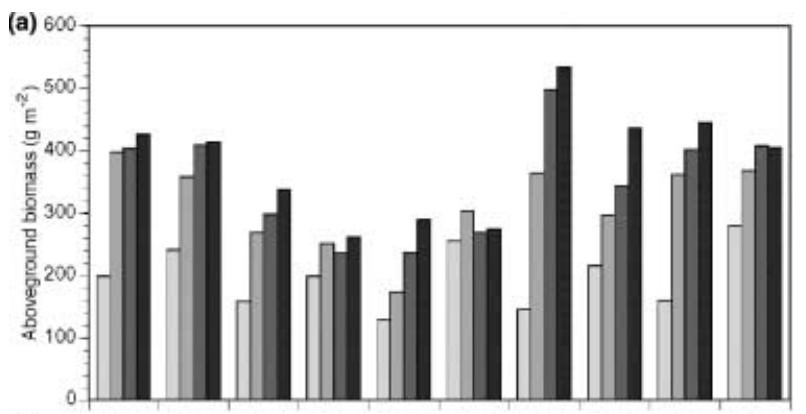

(b)

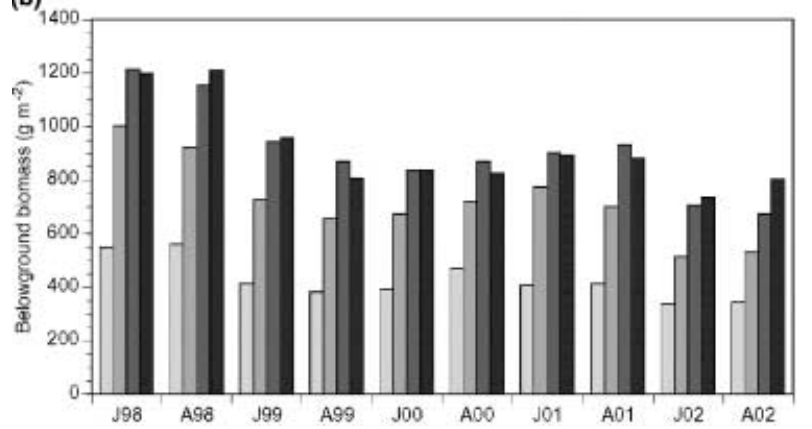

Figure 1 Aboveground (a) and belowground (b) biomass for the June (J) and August (A) harvests of the 5 years (1998-2002) for one-, four-, nine-, and 16-species plots (left to right).
For belowground biomass, averaged across harvests, the model predicted belowground biomass within $5 \%$ at each diversity level and diversity explained only $1 \%$ of the variance of the residuals of the repeated measures model. Nine species significantly altered belowground biomass (Fig. 2), ranging from $-260 \mathrm{~g} \mathrm{~m}^{-2}$ (Lupinus June 2001) to $+830 \mathrm{~g} \mathrm{~m}^{-2}$ (Poa June 2001). These included three $\mathrm{C}_{3}$ grasses, two $\mathrm{C}_{4}$ grasses, two forbs, and two legumes. The effects of the presence of a given species varied by as much as $557 \mathrm{~g} \mathrm{~m}^{-2}$ over the 10 harvests. There was only a weak negative relationship between effects of species aboveground and belowground $\left(P=0.04, r^{2}=0.06\right)$ for those eight species that affected both significantly.

The effects of most species pairs were additive. Only nine of the 132 possible pairwise interactions for species effects aboveground were significant and nine of 72 belowground. The majority of the significant interactions between species effects on biomass were negative, especially those between species that had large positive effects (Fig. 3). Negative interactions between effects produce diminishing increases in biomass with increasing diversity. If there were no statistical interactions between species with positive main effects, biomass would increase linearly with diversity. If there were positive statistical among species that had positive main effects, biomass would increase exponentially over the diversity range of the experiment.

Over the 5 years, the consistently positive diversity effect is maintained in part by more diverse plots being more likely to have species that differ in their relative growth rate and/ or seasonal phenology. For example, if slow-growing species were not present, the diversity effect would have declined in strength over time both aboveground and belowground. The slope of the square-root transformed diversity-biomass relationship would have declined significantly over time if slow-growing species had not increased their effects beyond the June 1998 values $\left[r^{2}=0.48, F_{\text {time }}=7.6, P=0.02\right.$ with time coded continuously equivalent to harvest number (1-10)]. Similarly, belowground, the diversity effect would have been less in later harvests without slow-growing species increasing their effects beyond those of the first harvest $\left(r^{2}=0.57, F_{\text {time }}=10.8, P=0.01\right)$. For example, instead of a $460 \pm 53 \mathrm{~g} \mathrm{~m}^{-2}$ belowground increase in biomass from one to 16 species in August 2002, biomass would have only increased $180 \pm 29 \mathrm{~g} \mathrm{~m}^{-2}$.

Seasonal offsets in effects between cool- and warmseason species is another factor that maintains diversity effects over time (Fig. 2). Aboveground, species such as the cool-season Lupinus have consistently more positive effects in June than August, while the converse is true for species such as warm-season Lespedeza. Belowground species such as the cool-season $\mathrm{C}_{3}$ forb Achillea and the warm-season $\mathrm{C}_{4}$ grass Andropogon were offset seasonally in their effects. 

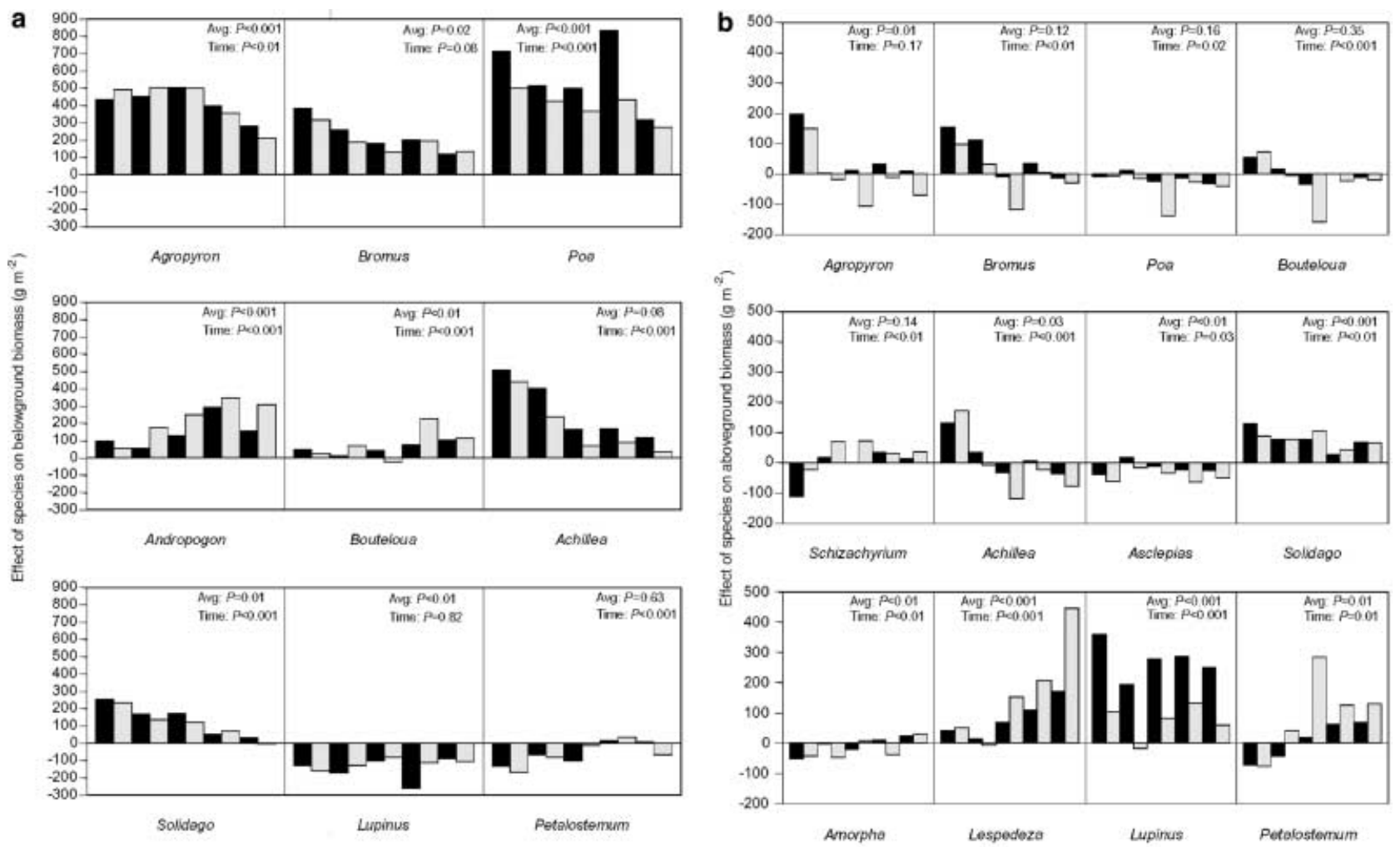

Figure 2 Effects of the presence of species on aboveground (a) and belowground (b) biomass for each of the 10 harvests (June 1998-August 2002 , left to right). Species effects were calculated as the estimates of the main effects plus one half of the estimates of any interactions with other species. Included are the results from the repeated measures analysis that denotes whether there were significant effects of species on average (Avg) across all harvests (between-subjects effects) and whether the effects varied significantly over time (Time; within-subjects effects). For all factors, between-subjects and within-subjects effects were significant aboveground (between: $F$-test, $F=24.9, P<0.001$; within: Wilks' Lambda, $F=4.5, P<0.001$ ) and belowground (between: $F$-test, $F=55.3, P<0.001$; within: Wilks' Lambda, $F=3.6$, $P<0.001)$.

Although some species were able to maintain or increase their effects during the dry 2000 summer (e.g. Petalostemum), there was insufficient compensatory growth aboveground by these species to maintain the diversity effect. Species such as Agropyron and Poa had much more negative effects on biomass after the dry 2000 summer than during other times (Fig. 2).

Variance in biomass over time for plots of different diversity can be due to differences in assemblage composition or differences in the production of individual species for plots of different diversity. Although we could not separate the influence of these two sources of variation, the biomass of high diversity plots showed less variance both aboveground $(P<0.001$; SD $=168,142,118,109$ for one-, four-, nine-, 16-species plots compared at the mean biomass) and less variance belowground $(P=0.03$, $\mathrm{SD}=272,286,251,243)$.

Different species were not only important in generating the positive diversity effect, but also in the biomass response of ecosystems to elevated $\mathrm{CO}_{2}$ and $\mathrm{N}$. The $\mathrm{N}$ response of belowground biomass was dependent on the presence of the $\mathrm{C}_{3}$ grass Poa (Fig. 4). In the repeated measures ANOvA, averaged across the 10 harvests, elevated $\mathrm{N}$ increased belowground biomass by $58 \mathrm{~g} \mathrm{~m}^{-2}$ when Poa was not present, although there was nearly no N effect during 1998 and 1999. On average, when Poa was present, $\mathrm{N}$ increased biomass by $286 \mathrm{~g} \mathrm{~m}^{-2}$. Aboveground, the opposite pattern occurred during 2000-2002, when the presence of Lespedeza decreased the $\mathrm{N}$ effect $\left(+81 \mathrm{~g} \mathrm{~m}^{-2}\right.$ vs. $-10 \mathrm{~g} \mathrm{~m}^{-2}$ ) (Fig. 4). Although there were interactions between $\mathrm{N}$ supply and individual species, $\mathrm{N}$ treatment remained significant in the repeated measures ANOVA models, implying that there was still a significant response of biomass to elevated $\mathrm{N}$ when the above-mentioned species were not present. Although elevated $\mathrm{CO}_{2}$ increases aboveground biomass and belowground biomass on average $\left(+15 \mathrm{~g} \mathrm{~m}^{-2}\right.$ and $+52 \mathrm{~g} \mathrm{~m}^{-2}$ ), the response of biomass was not altered by the presence of any individual species. 


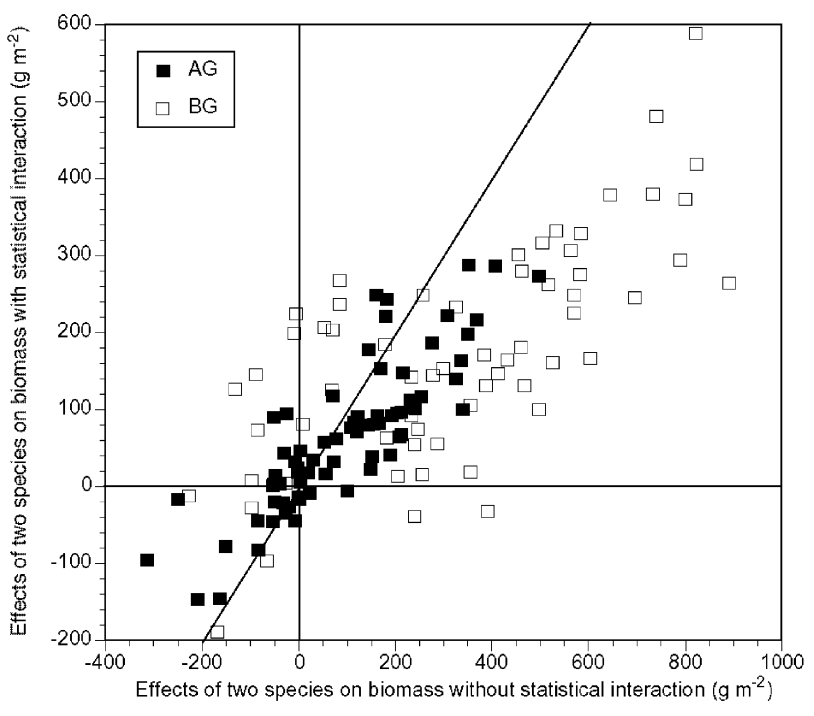

Figure 3 Relationship between the effects of two species on above (घ) and belowground ( $\square$ ) biomass if there is no statistical interaction and main effects are additive ( $x$-axis) and when statistical interactions are included ( $y$-axis). Each point represents the effects of two species that a significant statistical interaction in the repeated measures ANOVA on biomass for a given harvest. The $1: 1$ line represents the relationship if there was no statistical interaction between species (additive effects). Points to the left are positive statistical interactions between species effects, to the right are negative.

\section{DISCUSSION}

In a world experiencing increasing $\mathrm{CO}_{2}$ and $\mathrm{N}$, and shifting composition and diversity, there is great complexity in the roles of individual species and their interactions with other species in diverse assemblages. In many cases, the functioning of the communities at different diversity levels are much more complex than a simple sampling effect in which the presence of one species generates an increase in biomass with increasing diversity. Thirteen of the 16 species that we planted had statistically significant effects on aboveground and/or belowground biomass. Although the magnitude of some of the species effects could be at times small, even rare species can affect the functioning of ecosystems (Lyons \& Schwartz 2001) and thus it is difficult to infer biological significance from statistical significance. The species that had no statistical significance on either aboveground or belowground biomass (Koeleria, Sorghastrum, Anenome) are fairly different ecologically and we can offer no potential generalizations about which species are not likely to affect assemblage biomass.

Species differed in their effects seasonally, during the transient dynamics of community development (successionally), and in response to climatic variation. Collectively, these complementary species effects on assemblage biomass
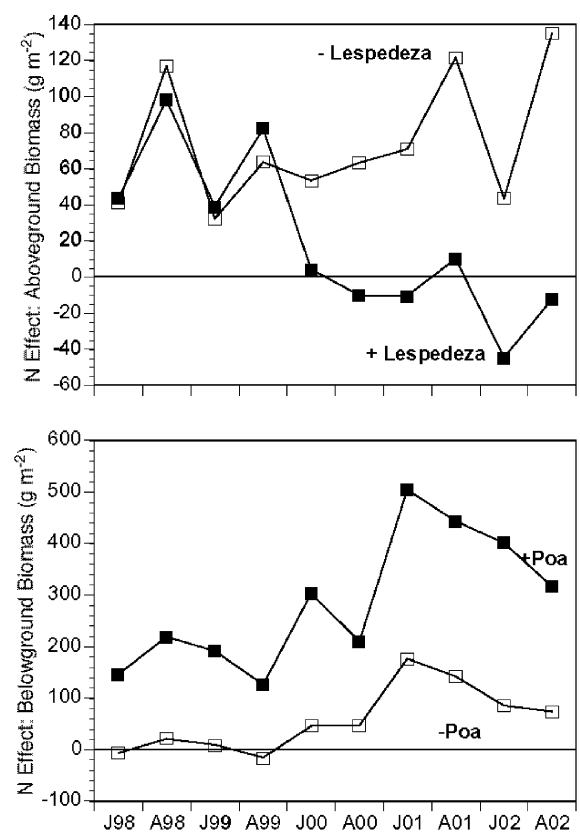

Figure 4 Dependence of $\mathrm{N}$ effects on aboveground biomass on the presence of Lespedeza [with Lespedeza ( $\mathbf{\square}$ ) and without Lespedeza $(\square)]$ and of $\mathrm{N}$ effects on belowground biomass on the presence of Poa [with Poa $(\mathbf{\square})$ and without Poa $(\square)$ ] over the 10 harvests [June 1998 (J98)-August 2002 (A02)].

caused more species-rich assemblages to maintain higher levels of biomass over time with less variability than less diverse assemblages. Diverse plots are more likely to have species that are offset in their seasonality of production, successional status, or response to variation in climate, such that a decrease in the production of one species is compensated for by an increase in production by another species.

Niklaus et al. (2001) also found that communities that had a more diverse mix of fast- and slow-growing species maintained greater productivity over time. In their study, fast-growing species had high productivity early in the experiment when nitrogen availability was high and after a few years they were replaced by slow-growing species as nitrogen availability declined. In our experiment, $\mathrm{N}$ availability declined over time, too (P. Reich unpublished). The decline in the effects of fast-growing species was not due solely to the increase in slow-growing species. Even in monoculture, the biomass of species such as Agropyron and Bromus declined after 1998 (data not shown). The lack of interaction between the fast-growing species and $\mathrm{N}$ addition (except Poa) implies that $\mathrm{N}$ fertilization did not reverse these species declines, but does not necessarily mean that a decrease in $\mathrm{N}$ supply is not responsible for the decline of fast-growing species since the decrease in $\mathrm{N}$ supply over time may have been greater than the $\mathrm{N}$ addition rate. 
Even if the successional patterns that we observed were associated with changes in $\mathrm{N}$ availability, these transient effects are not limited to experiments. In many grasslands, a large fraction of the ground is disturbed each year by animals (e.g. gophers at Cedar Creek) and would experience situations that are qualitatively similar to establishment in BioCON - bare soil with high nutrient availability. The relatively weaker initial biodiversity effect in an experiment in an adjacent field at Cedar Creek (Tilman et al. 2001) may be due to a lack of performance from fast-growing species due to either soil or climatic conditions during the first few years.

Statistical interactions between main effects indicate a significant change in biomass when both species are present relative to what was expected based on their individual effects, causing main effects to be non-additive. Generally, there were negative interactions between species that had positive effects and these interactions were more negative the larger the sum of the main effects, although having both species still led to greater biomass than if just one of the species was present. This specific pattern of negative statistical interactions leads to an asymptotic relationship between diversity and biomass whereby there are diminishing increases in biomass as the likelihood of negative statistical interactions increases with increasing diversity. As a particular statistical interaction does not necessarily imply inhibition or facilitation, more detailed analyses of the intercepts, main effects, and interactions are needed, but are beyond the scope of this paper. A minority of interactions were positive in sign, but these generally involved species that had negative main effects, such as the legumes. This indicates that the negative effects of the species were not as severe in the presence of the other species.

The response of assemblages to increased resource availability has been shown to be greater for high diversity communities (Reich et al. 2001a). We show that this response is often dependent on the presence of a single species, which low diversity assemblages are less likely to have. In the first harvests, there was virtually no response in belowground biomass to $\mathrm{N}$ unless Poa was present, while in later harvests there was virtually no response in aboveground biomass to $\mathrm{N}$ unless Lespedera wasn't present. The $\mathrm{N}_{2}$-fixing legume Lespedeza is likely to decrease its $\mathrm{N}_{2}$-fixation when inorganic $\mathrm{N}$ is added, such that the additional $\mathrm{N}$ has a direct effect on production, but less of a net effect due to compensatory decreases in $\mathrm{N}_{2}$-fixation. Although a statistical interaction between $\mathrm{CO}_{2}$ and diversity was detected by Reich et al. (2001a), no one species was found to be responsible for this. This may imply multiple weak interactions between individual species and elevated $\mathrm{CO}_{2}$.

In conclusion, these results make a strong case for maintaining diverse plant assemblages and not just attempt- ing to determine the "best" species to maintain for a given location. The effects and interactions among species in diverse assemblages are complex and there was great complementarity among species in seasonal, successional, and climatic response differences with little relationship in species effects aboveground and belowground. While responses of assemblage biomass to $\mathrm{N}$ were dependent on the presence of individual species, responses to $\mathrm{CO}_{2}$ could not be ascribed to an individual species. How the BioCON species affect other aspects of the ecosystem such as $\mathrm{N}$ cycling (Niklaus et al. 2001; Mulder et al. 2002) and invasion resistance (Knops et al. 1999; Dukes 2001; Kennedy et al. 2002) remains to be seen, but is likely to further show the individuality of species.

\section{REFERENCES}

Aarssen, L.W. (1997). High productivity in grassland ecosystems: effected by species diversity or productive species. Oikos, 80, $183-184$.

Allison, G.W. (1999). The implications of experimental design for biodiversity manipulations. Am. Nat., 153, 26-45.

Chapin, F.S., Zavaleta, E.S., Eviner, V.T., Naylor, R.L., Vitousek, P.M., Reynolds, H.L. et al. (2000). Consequences of changing biodiversity. Nature, 405, 234-242.

Craine, J.M. \& Reich, P.B. (2001). Elevated $\mathrm{CO}_{2}$ and nitrogen supply alter leaf longevity of grassland species. New Phytol., 150, 397-493.

Craine, J.M., Wedin, D.A. \& Reich, P.B. (2001). The response of soil $\mathrm{CO}_{2}$ flux to changes in atmospheric $\mathrm{CO}_{2}$, nitrogen supply, and plant diversity. Glob. Change Biol., 7, 947-953.

Dukes, J.S. (2001). Biodiversity and invasibility in grassland microcosms. Oecologia, 126, 563-568.

He, J.-S., Bazzaz, F.A. \& Schmid, B. (2002). Interactive effects of diversity, nutrients and elevated $\mathrm{CO}_{2}$ on experimental plant communities. Oikos, 97, 337-348.

Hector, A., Schmid, B., Beierkuhnlein, C., Caldeira, M.C., Diemer, M., Dimitrakopoulos, P.G. et al. (1999). Plant diversity and productivity experiments in European grasslands. Science, 286, 1123-1127.

Huston, M.A. (1997). Hidden treatments in ecological experiments: re-evaluating the ecosystem function of biodiversity. Oecologia, 110, 449-460.

Kennedy, T.A., Naeem, S., Howe, K.M., Knops, J.M.H., Tilman, D. \& Reich, P. (2002). Biodiversity as a barrier to ecological invasion. Nature, 417, 636-638.

Knops, J.M.H., Tilman, D., Haddad, N.M., Naeem, S., Mitchell, C.E., Haarstad, J. et al. (1999). Effects of plant species richness on invasion dynamics, disease outbreaks, insect abundances and diversity. Ecol. Lett., 2, 286-293.

Lee, T.D., Tjoelker, M.G., Ellsworth, D.S. \& Reich, P.B. (2001). Leaf gas exchange responses of 13 prairie grassland species to elevated $\mathrm{CO}_{2}$ and increased nitrogen supply. New Phytol., 150, 405-418.

Loreau, M. \& Hector, A. (2001). Partitioning selection and complementarity in biodiversity experiments. Nature, 412, 72-76.

Lyons, K.G. \& Schwartz, M.W. (2001). Rare species loss alters ecosystem function-invasion resistance. Ecol. Lett., 4, 358-365. 
McGrady-Steed, J., Harris, P.M. \& Morin, P.J. (1997). Biodiversity regulates ecosystem predictability. Nature, 390, 162-165.

Mulder, C.P.H., Jupponen, A., Högberg, P. \& Huss-Danell, K. (2002). How plant diversity and legumes affect nitrogen dynamics in experimental grassland communities. Oecologia, 133, 412-421.

Naeem, S. \& Li, S. (1998). Consumer species richness and autotrophic biomass. Ecology, 79, 2603-2615.

Niklaus, P.A., Leadley, P.W., Schmid, B. \& Korner, C. (2001). A long-term field study on biodiversityXelevated $\mathrm{CO}_{2}$ interactions in grassland. Ecol. Monogr., 71, 341-356.

Reich, P.B., Knops, J.M.H., Tilman, D., Craine, J., Ellsworth, D., Tjoelker, M. et al. (2001a). Plant diversity enhances ecosystem responses to elevated $\mathrm{CO}_{2}$ and nitrogen deposition. Nature, 410, 809-812.

Reich, P.B., Tilman, D., Craine, J., Ellsworth, D., Tjoelker, M., Knops, J. et al. (2001b). Do species and functional groups differ in acquisition and use of $\mathrm{C}, \mathrm{N}$ and water under varying atmospheric $\mathrm{CO}_{2}$ and $\mathrm{N}$ deposition regimes? A field test with 16 grassland species. New Phytol., 150, 435-448.

Sala, O.E., Chapin, F.S., Armesto, J.J., Berlow, E., Bloomfield, J., Dirzo, R. et al. (2000). Global biodiversity scenarios for the year 2100. Science, 287, 1770-1774.

Schmid, B., Hector, A., Huston, M.A., Inchausti, P., Nijs, I., Leadley, P.W. \& Tilman, D. (2002). The design and analysis of biodiversity experiments. In: Biodiversity and Ecosystem Functioning:
Synthesis and Perspectives (eds Loreau, M., Naeem, S. \& Inchausti, P. ). Oxford University Press, Oxford, pp. 61-78.

Shaw, M.R., Zavaleta, E.S., Chiarelo, N.R., Clelan, E.E., Mooney, H.A. \& Field, C.B. (2002). Grassland responses to global environmental changes suppressed by elevated $\mathrm{CO}_{2}$. Science, 298 , 1987-1990.

Tilman, D. \& Downing, J.A. (1994). Biodiversity and stability in grasslands. Nature, 367, 363-365.

Tilman, D., Reich, P.B., Knops, J., Wedin, D., Mielke, T. \& Lehman, C. (2001). Diversity and productivity in a long-term grassland experiment. Science, 294, 843-845.

Tjoelker, M.G., Oleksyn, J., Lee, T. \& Reich, P.B. (2001). Direct inhibition of leaf dark respiration by elevated $\mathrm{CO}_{2}$ is minor in 12 grassland species. New Phytol., 150, 419-424.

Vitousek, P.M. (1994). Beyond global warming: ecology and global change. Ecology, 75, 1861-1876.

Wardle, D. (1998). A more reliable design for biodiversity study? Nature, 394, 30.

Editor, I. F. Woodward

Manuscript received 29 January 2003

First decision made 5 March 2003

Manuscript accepted 31 March 2003 